\title{
A Study of the English Teachers' Burnout in a Local Comprehensive University in China
}

\author{
Yougen Lou', Liyou Chen ${ }^{2 *}$ \\ ${ }^{1}$ School of Foreign Studies, Yangtze University, Jingzhou, China \\ ${ }^{2}$ Haikou Council for the Promotion of Youth Entrepreneurship and Employment, Haikou, China \\ Email: "louyougen@163.com
}

Received 10 March 2016; accepted 17 April 2016; published 20 April 2016

Copyright (C) 2016 by authors and Scientific Research Publishing Inc.

This work is licensed under the Creative Commons Attribution International License (CC BY). http://creativecommons.org/licenses/by/4.0/

(c) (i) Open Access

\begin{abstract}
Many English teachers in colleges or universities complain about work stress. The purpose of the present study was to learn about English teachers' actual burnout situation and to seek intervention; a questionnaire survey and written interviews were conducted in a local comprehensive university in China. 79 English teachers were as the participants in this study. The results in this study showed that: 1) The participants experienced a low to medium level of burnout; 2) significant differences were found in the aspects of English teachers' workload and English teachers in departments. No significant differences were found in the aspects of the gender; 3) meanwhile, the results of the interviews indicate five causes of burnout: Factors related to the job, students, management, teacher development and family. Internal and external supports are categorized as the burnout reducers. As for intervention, teachers, the organization, society and family should work together to buffer the burnout syndrome. The findings would help university administrators consider such factors as important in the effectiveness of English teachers.
\end{abstract}

\section{Keywords}

English Teachers, Burnout, Local Comprehensive University

\section{Introduction}

The phenomenon of burnout is serious for teachers' well-being. The term "burnout" originated in Graham Greene's novel A Burnt-out Case (1960), in which a desperate architect quits his job and escapes into the African jungle (cited in Maslach, 1976). Freudenberger (1974, p. 159) first used "burnout" to describe a social phenomenon, in which human service professionals are so exhausted that they can no longer perform their tasks ef-

\footnotetext{
"Corresponding author.
} 
fectively. Maslach (1976, p. 7) defined burnout as a condition in which one loses all concerns and feelings toward the people one works with and comes to treat them as impersonal objects. Burnout is a psychological syndrome which results from chronic stressors on the workplace (Maslach et al., 2001). Burnout is a universal phenomenon (Aloe et al., 2014) and many studies have found that teachers have the highest levels of burnout among human service workers (Maslach et al., 1996; Schaufeli \& Enzmann, 1998; Pietarinen et al., 2013).

\section{Literature Review}

\section{Teacher Burnout}

Burnout is defined as Ban erosion of engagement that what started out as important, meaningful, and challenging work becomes unpleasant, unfulfilling, and meaningless (Maslach et al., 2001: p. 416). Burnout occurs in professions that deal with human services, and teaching has been considered as a profession that high levels of burnout have been reported (Maslach et al., 1996; Richardson \& Watt, 2006). There are three main dimensions in burnout, emotional exhaustion, depersonalization, and reduced personal accomplishment. Emotional exhaustion refers to feelings of being emotionally overextended (Maslach et al., 2001).

A line of research has been done to investigate teachers' burnout in many countries. American public school teachers suffered from moderate to high levels of burnout (Hock, 1988) while secondary special education teachers in America experienced high levels of emotional exhaustion (Embich, 2001). Papastylianou et al. (2009) reported medium levels of burnout among Greek primary school teachers (p. 295). Greek female primary and secondary school teachers experienced significantly higher levels of burnout than the male teachers (Antoniou et al., 2006). Anil Shukla \& Tripta Trivedi (2008) investigated the status of burnout among secondary school teachers and assess its extent in Indian teachers. Jayakaran Mukundan \& Koroush Khandehroo (2010) investigated 120 primary and secondary English language teachers in Malaysia and they found burnout was evident at high levels between burnout and the English teachers' demographics of age and workload in Malaysia. Hadi Zarafshan et al. (2013) investigated the job burnout among Iranian elementary school teachers of students with Autism. Gholam Hassan Khajavy et al. (2016) explored 326 Iranian English as a Foreign Language (EFL) teacher's motivations in different language institutes for teaching and testing a model of burnout based on motivations and emotions using structural equation modeling (SEM). Korean upper-grade elementary school teachers experienced a greater degree of burnout than lower-grade teachers (Kim et al., 2009). According to Friedman (2000, p. 595), new teachers seem to undergo three stages in the first year of teaching: the slump $\rightarrow$ fatigue and exhaustion $\rightarrow$ adjustment. Dorman (2003) found that the school and classroom psychosocial environment might affect the burnout level of Australian teachers (p. 107). Howard and Johnson (2004) studied Australian primary school teachers' strategy of resisting stress and burnout (p. 399). All the above studies have been related to teachers' burnout of teachers in primary or secondary school and have been based on Maslach and Jackson's (1981, p. 99) three-dimensional concept of burnout and imply that it can provide a valid perspective to investigate teachers' burnout, even though almost all those studies have chosen primary or secondary school teachers as their participants.

In China, there were several studies conducted among the teachers' burnout of primary, secondary education. Zhang Yong and Yu Yue (2007) analyzed the harm done by Chinese secondary and elementary school teachers' burnout, defined its causes, and suggested preventive strategies. Primary and secondary school teachers in Macau reported average ranges of burnout in emotional exhaustion and depersonalization but low ranges of burnout in personal accomplishment (Luk et al., 2010: p. 489). And there were several studies conducted among the teachers' burnout of higher education in China. Shan Yu (2005) analyzed the Chinese "two-course" teachers' burnout in higher education institutions, the damage it causes, and its origins, exploring measures to prevent and alleviate it in order to arouse general concern for "two-course" teachers. Li J. (2007) surveyed 300 female teachers in medical universities in Henan Province and reported the demographic features of the participants' burnout in percentages, without ANOVA analysis of those variables, which somehow weakens its validity. Tian et al. (2011) investigated 177 female college teachers in Hainan Province and reported significant differences only in the subscale of reduced personal accomplishment. Kang and Qu (2011) surveyed 1238 teachers from vocational and technical colleges and reported $34.2 \%$ of burnout syndrome in emotional exhaustion, $11.2 \%$ in depersonalization and $15.7 \%$ in reduced personal accomplishment. The findings of the latter two studies do not agree with each other and indicate that the college teacher burnout situation needs further research.

For the English teachers' burnout, Cheng (2006) investigated 290 middle school English teachers and found 
no significant difference in variables such as gender and age, whereas reduced personal accomplishment differed significantly according to different teaching experience. And there were two studies concerned College English teachers. Xu (2010) surveyed 270 College English teachers and reported that $75.4 \%$ of them experienced a low to medium level of burnout. Wang (2010) investigated 75 female College English teachers and found that $41.89 \%$ of them were diagnosed with the burnout syndrome. Li Shunying (2015) investigated 37 English teachers' burnout in Chongqing medical university and reported that $29.73 \%$ of the participants experienced burnout. Since there is no agreement on the rates of College English teacher burnout identification in the above two studies, further research is needed into the burnout of College English teachers in China.

English teachers in a local comprehensive university in China were chosen for this study. This study wants to look for answers to the following questions:

1) Are these English teachers suffering from burnout?

2) If the answer is "Yes" to the first question, what is the degree of English teachers' burnout?

3) What factors may have caused the burnout syndrome?

4) What may be done to buffer?

\section{Methods}

\subsection{Subjects}

The subjects in this study were English teachers from Yangtze University. All the 144 English teachers from Yangtze University were invited to this study, but only 79 English teachers (69 female and 10 male) were volunteers to this study. The demographic features of the survey subjects were shown in Table 1.

\section{Table 1. The demographic features of the survey subjects.}

\begin{tabular}{|c|c|c|}
\hline Variables & Number $=79$ & Percentage \\
\hline \multicolumn{3}{|l|}{ Age (year) } \\
\hline Below 30 & 4 & 5.06 \\
\hline $30-50$ & 63 & 79.75 \\
\hline $50-60$ & 12 & 15.19 \\
\hline \multicolumn{3}{|l|}{ Teaching time (year) } \\
\hline Below 10 & 5 & 6.33 \\
\hline $11-20$ & 56 & 70.89 \\
\hline Over 20 & 18 & 22.78 \\
\hline \multicolumn{3}{|l|}{ Professional titles } \\
\hline Teaching assistant & 4 & 5.06 \\
\hline Lecture & 35 & 44.30 \\
\hline Associate professor & 37 & 46.84 \\
\hline Professor & 3 & 3.80 \\
\hline \multicolumn{3}{|l|}{ Educational background } \\
\hline No degree & 1 & 1.27 \\
\hline Bachelor’s degree & 4 & 5.06 \\
\hline Master’s degree & 69 & 87.34 \\
\hline Doctoral degree & 5 & 6.33 \\
\hline \multicolumn{3}{|l|}{ Departments } \\
\hline Public English department (for non-English-majored students) & 41 & 51.90 \\
\hline English-major department (for English-majored students) & 38 & 48.10 \\
\hline \multicolumn{3}{|l|}{ Workloads } \\
\hline Below 10 hours/week & 12 & 1.27 \\
\hline 11 - 20 hours/week & 38 & 56.97 \\
\hline Over 21 hours/week & 29 & 41.76 \\
\hline
\end{tabular}




\subsection{Instruments}

In order to check the effects of burnout among English teacher in Yangtze university, two types of instruments were employed in this study: burnout questionnaires and interviews.

Burnout questionnaire The questionnaire consisted of three parts. Part One was an introduction to its purpose and rating method. Part Two contained the demographic information, including gender, age, teaching time, professional titles, educational background, workload and teaching courses. Part Three was the burnout inventory. The Maslach Burnout Inventory (MBI-educator survey) was developed by Maslach and Jackson (1981, p. 113). It contained 22 items for the three subscales, with 9 items for emotional exhaustion (EE), 5 items for depersonalization (DP) and 8 items for reduced personal accomplishment (PA).

The Maslach Burnout Inventory with a 5-point scale ranging from “Almost Never” to "Almost Always” was used to score each item. A high score indicates a more intense experience of burnout. This instrument has been used many times in different countries and has revealed satisfactory and stable internal consistence, factorial and construct validity (Dorman, 2003; Kim et al., 2009; Luk et al., 2010). For the current study, Cronbach’s alphas were .87 for EE, .71 for DP, and .82 for PA, all of which were over .70, indicating that the instrument was valid for this study.

Interview All 79 subjects participated in this study were interviewed via QQ (a kind of on-line instant message service tool in China) and were filled out the interview questionnaire about the following questions: 1) Do you have the feeling of being burned-out? 2) If your answer to the first question is yes, what do you think may have led to your burnout? 3) How can you buffer your burnout according to your opinion?

\subsection{Data-Collection}

The survey was conducted in September, 2014. The burnout questionnaires were distributed to all the 79 English teachers and 79 responses were collected with complete data were used for the data analysis.

The interviews were conducted in November, 2014. The interview questions in written form, in Chinese, were sent through QQ and e-mail to 79 colleagues, all 79 interview questionnaires were available. The time of data-collection of interviews of 79 colleagues were spent in three months.

\subsection{Data-Processing}

SPSS 17.0 was used to process the data in this study. T-test was conducted to determine whether the burnout experienced by the participants differed significantly by workload, gender and department (departments divided by teaching for non-English-majored students or English-majored students). The interview responses were analyzed for themes.

\section{Results}

\subsection{The English Teachers' Burnout Situation Indicated by the Survey}

\subsubsection{The General English Teachers' Burnout Situation}

As shown in Table 2, the general English teachers' burnout situation in the survey was shown that EE $(\mathrm{M}=2.95$, $\mathrm{S}=1.18)$, DP $(\mathrm{M}=2.85 \mathrm{~S}=.95)$, PA $(\mathrm{M}=2.97, \mathrm{~S}=.97)$. The average of means of two subscales of English teachers' burnout (EE and DP) was lower 3 points indicated that English teachers suffered a low level to medium of burnout.

Table 2. The general English teachers' burnout situation.

\begin{tabular}{cccc}
\hline Subscales of burnout & N & M & S \\
\hline EE & 79 & 2.95 & 1.18 \\
DP & 79 & 2.85 & .95 \\
PA & 79 & $2 . .97$ & .97 \\
\hline
\end{tabular}

$\mathrm{N}$ for number; $\mathrm{M}$ for Mean; S for standard deviation; EE for emotional exhaustion; DP for depersonalization (DP); PA for reduced personal accomplishment. 


\subsubsection{The Differences of English Teachers' Burnout among Different Workload}

Workload, on the basis of teaching hours per week, was categorized in three interval groups of below 10, 11 - 20, and over 21 and was scrutinized with relation to each of the burnout dimensions. As shown in Table 3, there was a significant relation with reference to the emotional exhaustion between the two categories of $11-20$, and over 21. However, the first group consisting of 12 teachers with less than 10 hours of teaching did not show a high degree of emotional exhaustion.

As shown in Table 4, there was a significant relation with reference to the depersonalization between the two categories of workload 11 - 20 hours/week, and over 20 hours/week. However, the first group consisting of 12 teachers with less than 10 hours/week of teaching did not show a high degree of depersonalization.

As shown in Table 5, there was a significant relation with reference to the reduced personal accomplishment between the two categories of workload below10hours/week and 11 - 20 hours/week whereas the ones with workload more than 21 hours in the same period of time as the others do not seem to have personal accomplishment problems.

\subsubsection{The Burnout Differences of English Teachers' Burnout between Genders}

As shown in Table 6, all the three subscales of burnout were no significant difference between female English teachers and male English teachers but female English teachers scored slightly higher than male English teachers.

\subsubsection{The Differences of English Teachers' Burnout between Departments}

As shown in Table 7, there were significant difference between English teachers in public English department and English teachers in English-major department at the subscale of Emotional Exhaustion $(\mathrm{t}=2.19, p=.04)$ and Depersonalization $(\mathrm{t}=2.25, p=.03)$. English teachers in public English department for teaching nonEnglish-major students scored higher than English teachers in English-major department for teaching English-major students.

Table 3. Statistics and one-sample t-test for Emotional Exhaustion with reference to workload.

\begin{tabular}{ccccc}
\hline Workload hours/week & N & M & S & P \\
\hline Below 10 & 12 & 2.17 & .94 & .06 \\
$11-20$ & 38 & 2.79 & 1.07 & $.03^{*}$ \\
Over 21 & 29 & 3.00 & 1.22 & $.04^{*}$ \\
\hline
\end{tabular}

$\mathrm{N}$ for number; $\mathrm{M}$ for Mean; $\mathrm{S}$ for standard deviation; EE for emotional exhaustion; ${ }^{*} p<.05$

Table 4. Statistics and one-sample t-test for depersonalization with reference to workload.

\begin{tabular}{ccccc}
\hline Workload hours/week & N & M & S & P \\
\hline Below 10 & 12 & 2.50 & .80 & .07 \\
$11-20$ & 38 & 3.08 & .10 & $.04^{*}$ \\
Over 21 & 29 & 3.24 & .99 & $.03^{*}$ \\
\hline
\end{tabular}

$\mathrm{N}$ for number; $\mathrm{M}$ for Mean; $\mathrm{S}$ for standard deviation; EE for emotional exhaustion; ${ }^{*} p<.05$

Table 5. Statistics and one-sample t-test for reduced personal accomplishment with reference to workload.

\begin{tabular}{ccccc}
\hline Workload hours/week & $\mathbf{N}$ & $\mathbf{M}$ & $\mathbf{S}$ & 1.24 \\
\hline Below 10 & 12 & 3.08 & $.01^{*}$ & \\
$11-20$ & 38 & 3.24 & .08 & .96 \\
Over 21 & 29 & 3.28 & .08 \\
\hline
\end{tabular}

$\mathrm{N}$ for number; $\mathrm{M}$ for Mean; S for standard deviation; EE for emotional exhaustion; ${ }^{*} p<.05$ 
Table 6. The differences of English teachers’ burnout between genders.

\begin{tabular}{rccccccc}
\hline & Items & \multicolumn{2}{c}{ Female $(\mathbf{N}=\mathbf{6 9})$} & \multicolumn{2}{c}{ Male $(\mathbf{N}=\mathbf{1 0})$} & \multicolumn{3}{c}{ T-test } \\
\cline { 2 - 8 } Subscales of burnout & $\mathbf{M}$ & $\mathbf{S}$ & $\mathbf{M}$ & $\mathbf{S}$ & $\mathbf{t}$ & $\mathbf{p}$ \\
\hline EE & 2.92 & 1.19 & 2.78 & 1.10 & .82 & .43 \\
DP & 2.86 & .95 & 2.80 & .94 & 1.08 & .31 \\
PA & 2.83 & .98 & 2.79 & .88 & -.36 & .73 \\
\hline
\end{tabular}

$\mathrm{N}$ for number; $\mathrm{M}$ for Mean; S for standard deviation; EE for emotional exhaustion; DP for depersonalization (DP); PA for reduced personal accomplishment.

Table 7. The differences of English teachers' burnout between departments.

\begin{tabular}{|c|c|c|c|c|c|c|}
\hline \multirow{2}{*}{ Subscales of burnout } & \multicolumn{2}{|c|}{ Public English department $(\mathrm{N}=41)$} & \multicolumn{2}{|c|}{ English-major department $(\mathrm{N}=\mathbf{3 8})$} & \multicolumn{2}{|c|}{ T-test } \\
\hline & $\mathbf{M}$ & S & $\mathbf{M}$ & $\mathbf{S}$ & $\mathbf{t}$ & $\mathbf{p}$ \\
\hline $\mathrm{EE}$ & 3.39 & .86 & 2.84 & 1.05 & 2.19 & $.04^{*}$ \\
\hline $\mathrm{DP}$ & 3.34 & .96 & 2.93 & .82 & 2.25 & $.03^{*}$ \\
\hline PA & 2.82 & .96 & 3.16 & .92 & -1.53 & .135 \\
\hline
\end{tabular}

$\mathrm{N}$ for number; $\mathrm{M}$ for Mean; $\mathrm{S}$ for standard deviation; EE for emotional exhaustion; DP for depersonalization (DP); PA for reduced personal accomplishment; ${ }^{*} \mathrm{p}<.05$.

\subsection{The Causes of English Teachers' Burnout Indicated by Interviews}

The survey and the interviews suggested that many English teachers in the local comprehensive university in this study were experiencing burnout, although their level of burnout may differ from persons to persons. What factors may have caused the burnout syndrome among the interviews' respondents?

The causes of English teachers' burnout were categorized into five types of stressors: factors related to the job, students, management, teacher development and family.

Thirty respondents reported job-related stressors. Ten respondents said that English teaching was boring and routine, without much change in the teaching content and method. Nine respondents said that the teaching time was very long and the workload was heavy. Five respondents reported a low sense of accomplishment. English teaching lacked challenge and excitement and gradually led to burnout. Six respondents said that it was exhausting to go to work very early in the morning to avoid being late for lectures and go home very late in the evening.

Thirteen respondents mentioned the burnout stressor from students' incompetence. Seven respondents stated that the students in this local comprehensive university were not interested in learning English and their competence in English were not good. Six respondents said that, from 1999 to now, the enrollment for students to enter colleges or universities was expanded, which led to many incompetent students entering the university. However, these students did not want to spend time and energy to enhance their learning competence and often blamed the teachers for their unsuccessful learning.

Eleven respondents reported management-related stressors led to burnout. Three respondents said that it was very subjective and unfair to pay the teachers according to the results of the students' assessment of the teaching and good teachers often could not get good results while some excellent results were "ridiculous." Four respondents said that the ecological environment was not good and that teachers had to write a lot of academic papers to meet the different requirements from the university. Another four respondents criticized the inhuman policy regarding "teaching accidents" and stated that the management had no tolerance at all for any errors made by the teachers.

Fourteen respondents regarded the lack of in-service training as the burnout stressor. They said that teaching was a physical, mental and spiritual job, but English teachers did not have the chances to get in-service training and this led to the lack of new ideas and communications with experts about course teaching, which caused the lack of accomplishment.

Eleven respondents reported family-related stressors led to burnout. They complained that as female English 
teaching, they had to keep the balance between English teaching in university and taking care of family members, which led to them a lot of stressors.

\subsection{The Supports to Buffer English Teachers' Burnout Indicated by Interviews}

Chang (2009) categorized the sources of burnout into three main factors, individual, organizational, and transactional. Individual factors are related to demographical data such as age, gender, and teaching experience. Organizational factors are related to characteristics of the job and workplace such as inadequate salary, class size, and socioeconomic status of the institution. Finally, transactional factors refer to interaction of individual and organizational factors such as teacher's judgment of student misbehavior and norms of student-teacher interaction.

The interviewees' suggestions for buffering burnout were categorized into three types, external, internal and transactional supports. External supports contained the university providing English teachers chances to learn from others and to make some changes in teaching methods, respecting teachers' opinion when assigning work, offering teachers the chance to get in service training, reforming the teacher assessment system and improving the ecological environment of the university; family members help English teachers reduce stressors from family. Internal supports include self-encouragement, being optimistic and improving their viewpoint about their career development. Transactional supports contained the university provided supports to teacher's judgment of student misbehavior. However, ten respondents said that nothing could be done to change the situation and they had to endure the "torture" of burnout. This negative attitude showed a sense of desperation and it may be not good to their job and health.

\section{Discussion}

The results in this study show that the phenomenon of English teachers' burnout is a serious issue that needs to be emphasized before the effects of English teachers' burnout lead to English teachers and university a lot of loss.

Wang and Guo's study shows significant correlation between occupational stress, teachers' burnout and mental health (cited in Luk et al., 2010: p. 493). In this study, although English teachers, in general, suffer a low degree of burnout, university administrations should pay attention to English teachers' burnout, because burned-out teachers tend to be irritable at home and in class, suffering from anxiety and feelings of powerlessness, accompanied by physical discomfort such as chronic fatigue, headaches, insomnia, shingles and heart palpitations (Howard \& Johnson, 2004: p. 400). They feel cynical and adopt a cold, distant, depersonalized attitude towards their job and the students, tending to minimize their involvement at work and abandon their ideals, losing the confidence to make a difference professionally (Friedman, 2000: p. 605). They are prone to lose their goals, will and energy, to have less enthusiasm for their work and to exhibit a decreased level of teaching performance (Kim et al., 2009: p. 476).

The findings of teachers' workload in this study agree with Jayakaran Mukundan \& Koroush Khandehroo's (2010) study about burnout among English language teachers in Malaysia. Jayakaran Mukundan \& Koroush Khandehroo's (2010) study investigates the relationship between English teachers' burnout and their age, but there no investigation of relationship between English teachers' burnout and their age in this study. The findings in Li Shunying's (2015) study and the findings in this study, both finds that English teachers in university suffers a low degree of burnout, and female English teachers' burnout scores a slightly higher than that of male English teachers, but there is no significant difference between them. Two subscales of burnout(EE and DP), there are significant differences between English teachers in the public English department and English teachers in the English-major department in this study, because usually, English teachers in the public English department give more students lectures than that of English teachers in the English-major department, and more non-English-majored students with incompetent English lead to stressors to English teachers in the public English department, which causes English teachers in the public English department more emotional exhaustion and depersonalization.

Solutions for teachers' burnout provided by William G. Cunningham (1983) were improvement of teacher status; rewarding ambition, commitment, motivation, and performance; job enrichment or redesign; pre-service stress preparation; teacher conditioning; improved supervision and support; implementing quality circles; joint student-parent-teacher problem solving; and participatory team leadership. According to the findings of the interviews, what the teachers can do is to keep psychologically healthy by depending on internal as well as exter- 
nal supports. As English teachers, we can learn lot of skills such as dancing, regular exercises to buffer the burnout. At the same time, all kinds of supports from society and family as the external supports to help English teachers to buffer the burnout. For example, university administrations improve the supervision to English teachers.

\section{Limitation and Suggestions for Further Research}

Though the present study has provided a survey detailed description of the English teachers' burnout, there are still some limitations of the study. Having the limitations in mind, suggestions for further research, therefore, can be put forward at the same time in order to achieve a lot thorough understanding of the teachers' burnout and buffering teachers' burnout.

Firstly, being time limitation (only a term) and other practical restrictions such as the subjects in the study consisted of only 79 English teachers in one university need to be broadened in further research.

Secondly, the instruments used to investigate the English teachers' burnout involve structured questionnaire and interviews. The study would be much better, if it were combined with other instruments such as observation, verbal report. More instruments should be used in investigation in further research.

Finally, participates in this study are the English teachers in a university. Results of other teachers' burnout such as senior school teachers, mathematics teacher, we need further research.

Despite of the restraints of the study, it is hoped that it can offer some guidelines for further research on teachers' burnout.

\section{Conclusion}

The phenomenon of burnout is serious for teachers' well-being also harmful to the organization teachers work for 79 English teachers were as the participants in this study. The results in this study suggested that the participants experienced a low to medium level of burnout. Significant differences were found in the aspects of English teachers' workload and English teachers in departments. No significant differences were found in the aspects of the gender. Meanwhile, the results of the interviews indicate five causes of burnout: factors related to the job, students, management, teacher development and family. Internal and external supports are categorized as the burnout reducers. As for intervention, teachers, the organization, society and family should work together to buffer the burnout syndrome. The author wished the findings would help university administrators consider such factors as important in the effectiveness of English teachers.

\section{References}

Aloe, A. M., Amo, L. C., \& Shanahan, M. E. (2014). Classroom Management Self-Efficacy and Burnout: A Multivariate Meta-Analysis. Educational Psychology Review, 26, 101-126. http://dx.doi.org/10.1007/s10648-013-9244-0

Antoniou, A. S., Polychroni, F., \& Vlachakis, A.-N. (2006). Gender and Age Differences in Occupational Stress and Professional Burnout between Primary and High-School Teachers in Greece. Journal of Managerial Psychology, 21, 682-690. http://dx.doi.org/10.1108/02683940610690213

Chang, M. L. (2009). An Appraisal Perspective of Teacher Burnout: Examining the Emotional Work of Teachers. Educational Psychology Review, 21, 193-218. http://dx.doi.org/10.1007/s10648-009-9106-y

Cheng, X. T. (2006). A Survey of English Teachers’ Professional Burnout. Educational Research on Foreign Languages \& Arts, 4, 47-52.

Cunningham, W. G. (1983). Teacher Burnout—Solutions for the 1980s: A Review of the Literature. The Urban Review, 15, 37-51. http://dx.doi.org/10.1007/BF01112341

Dorman, J. P. (2003). Relationship between School and Classroom Environment and Teacher Burnout: A LISREL Analysis. Social Psychology of Education, 6, 107-127. http://dx.doi.org/10.1023/A:1023296126723

Embich, J. L. (2001). The Relationship of Secondary Special Education Teacher's Roles and Factors That Lead to Professional Burnout. Teacher Education and Special Education: The Journal of the Teacher Education Division of the Council for Exceptional Children, 24, 58-69. http://dx.doi.org/10.1177/088840640102400109

Freudenberger, H. J. (1974). Staff Burn-Out. Journal of Social Issues, 30, 159-165. http://dx.doi.org/10.1111/j.1540-4560.1974.tb00706.x

Friedman, I. A. (2000). Burnout in Teachers: Shattered Dreams of Impeccable Professional Performance. Psychotherapy in Practice, 56, 595-606. http://dx.doi.org/10.1002/(sici)1097-4679(200005)56:5<595::aid-jclp2>3.0.co;2-q 
Hock, R. R. (1988). Professional Burnout among Public School Teachers. Public Personnel Management, 17, 167-189. http://dx.doi.org/10.1177/009102608801700207

Howard, S., \& Johnson, B. (2004). Resilient Teachers: Resisting Stress and Burnout. Social Psychology of Education, 7, 399-420. http://dx.doi.org/10.1007/s11218-004-0975-0

Kang, Y. J., \& Qu, Z. L. (2011). A Survey of Job Burnout of Vocational School Teachers. Vocational and Technical Education, 32, 69-73.

Khajavy, G. H., Ghonsooly, B., \& Fatemi, A. H. (2016). Testing a Burnout Model Based on Affective-Motivational Factors among EFL Teachers. Current Psychology, 2, 1-11. http://dx.doi.org/10.1007/s12144-016-9423-5

Kim, M. Y., Lee, J. Y., \& Kim, J. (2009). Relationships among Burnout, Social Support, and Negative Mood Regulation Expectancies of Elementary School Teachers in Korea. Asia Pacific Education, 10, 475-482. http://dx.doi.org/10.1007/s12564-009-9045-9

Li, J. (2007). Investigation and Analysis of Factors Affecting Female Teachers' Occupational Weariness at Medical Colleges and Universities. Northwest Medical Education, 15, 828-830.

Li, S. Y. (2015). A Case Study of the English Teachers' Burnout in a Medical University in China. Chinese Journal of Applied Linguistics, 38, 234-245. http://dx.doi.org/10.1515/cjal-2015-0014

Luk, A. L., Chan, B. P. S., Cheong, S. W., \& Ko, S. K. K. (2010). An Exploration of the Burnout Situation on Teachers in Two Schools in Macau. Social Indicators Research, 95, 489-502. http://dx.doi.org/10.1007/s11205-009-9533-7

Maslach, C. (1976). Burned-Out. Human Behavior, 5, 7-22.

Maslach, C., \& Jackson, S. E. (1981). The Measurement of Experienced Burnout. Journal of Occupational Behavior, 2, 99-113. http://dx.doi.org/10.1002/job.4030020205

Maslach, C., Jackson, S. E., \& Leiter, M. P. (1996). Maslach Burnout Inventory Manual (3rd ed.). Palo Alto, CA: Consulting Psychologists Press.

Maslach, C., Schaufeli, W. B., \& Leiter, M. P. (2001). Job Burnout. Annual Review of Psychology, 52, 397-422. http://dx.doi.org/10.1146/annurev.psych.52.1.397

Mukundan, J., \& Khandehroo, K. (2010). Burnout among English Language Teachers in Malaysia. Contemporary Issues in Education Research, 3, 71-76. http://dx.doi.org/10.19030/cier.v3i1.163

Papastylianou, A., Kaila, M., \& Polychronopoulos, M. (2009). Teachers’ Burnout, Depression, Role Ambiguity and Conflict. Social Psychological Education, 12, 295-314. http://dx.doi.org/10.1007/s11218-008-9086-7

Pietarinen, J., Pyhältö, K., Soini, T., \& Salmela-Aro, K. (2013). Reducing Teacher Burnout: A Socio-Contextual Approach. Teaching and Teacher Education, 35, 62-72. http://dx.doi.org/10.1016/j.tate.2013.05.003

Richardson, P. W., \& Watt, H. M. G. (2006). Who Chooses Teaching and Why? Profiling Characteristics and Motivations across Three Australian Universities. Asia-Pacific Journal of Teacher Education, 34, 27-56.

http://dx.doi.org/10.1080/13598660500480290

Schaufeli, W. B., \& Enzmann, D. (1998). The Burnout Companion to Study and Practice: A Critical Analysis. Philadelphia, PA: Taylor \& Francis.

Shukla, A., \& Tripta, T. (2008). Burnout in Indian Teachers. Asia Pacific Education Review, 9, 320-334. http://dx.doi.org/10.1007/BF03026720

Tian, Y., Jiu, W. H., Xu, F. F., \& Wang, X. D. (2011). Investigation and Analysis of Female Teachers' Burnout at Hainan Colleges and Universities. Northwest Medical Education, 19, 378-380.

Wang, X. J. (2010). Investigation and Analysis of the Burnout Status of College Female English Teachers. Journal of Jinan Vocational College, 1, 37-38, 41.

Xu, H. Y. (2010). A Study of University English Teachers' Professional Weariness. Education and Modernization, 3, 88-91.

Yong, Z., \& Yue, Y. (2007). Causes for Burnout among Secondary and Elementary School Teachers and Preventive Strategies. Chinese Education and Society, 40, 78-85. http://dx.doi.org/10.2753/CED1061-1932400508

Yu, S. (2005). Burnout in Higher Education “Two-Course” Teachers and Some Suggested Approaches to the Problem. Chinese Education and Society, 38, 53-60.

Zarafshan, H., Mohammadi, M. R., Ahmadi, F., \& Arsalani, A. (2013). Job Burnout among Iranian Elementary School Teachers of Students with Autism: A Comparative Study. Iranian Journal of Psychiatry, 8, 20-27. 